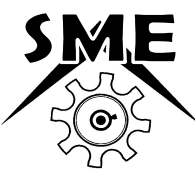

ESTD 2005

\title{
STUDY ON THE MECHANICAL PROPERTIES OF ROSELLE FIBER AND PALM SEED POWDER REINFORCED EPOXY HYBRID COMPOSITES
}

\author{
*Sakthi Vadivel K, Vigneshwaran K and Sivaraj C
}

Department of Mechanical Engineering, Builders Engineering College, Nathakadaiyur, Tamil Nadu- 638108, India

\begin{abstract}
Recently, due to increasing environmental concerns, scientists and researchers have been replacing synthetic fibers with natural fibers as the main component in composites. Roselle is one suitable natural fiber. The plant's history, physical description, cultural methods, and usages were explained to further understand this potential plant. It is clear that extensive research has been performed on the fiber extraction methods, properties, and possible surface treatments of Roselle fibers to enhance its properties in the manufacturing of natural-fiber-reinforced polymer composites.Also Epoxy hybrid Palm Seed powder with Roselle fiber to strengthen the materials; however, no review has covered the properties and applications of Roselle fibers and palm seed powders in detail. Thus we have investigated Tensile, Impact, Flexural and Water absorption test of Roselle fiber and Palm Seed powder composite. Therefore, a study was performed on Roselle fiber to determine its potential to enable a better selection of materials to produce composites for potential applications in the construction and building, automotive, and aerospace industries.
\end{abstract}

Keywords: Natural Fiber, Roselle fiber, Palm seed powder, Epoxy resin and Polymer Composites.

\section{Introduction}

Over a past few periods composites, plastics have been the dominant engineering materials. The areas of applications of composite materials have grown quickly and have even created new markets. New polymer resin matrix materials and high performance fibers of glass, carbon and aramid which have been familiarized recently have resulted in steady expansion in uses and volume of composites. This increase has resulted in obvious reduction of cost $[1,2]$.

Natural fiber composites mostly consists fibers of jute, cotton, hemp and non-conventional fibers such as Roselle and many empty fruit bunches. Natural fiber thermoplastic composites are attractive as they are inexpensive, harder and also can be assumed the look of wood in addition to all this they have more life- cycle. Natural fiber composites are attractive to industry because of their low density and environmental advantages over conventional composites $[3,4]$.

Investigated the mechanical properties of kenaffiber reinforced poly-l-lactic acid (PLLA) resin composites. This studyshowed that the tensile strength and modulus were higher than those of thekenaf fiber and the PLLA film themselves. Young's modulus and the tensile strength of the kenaf/PLLA composite having the fiber content of $70 \%$ volumewere coMParable to those of traditional composites. It was due to the stronginteraction between the kenaf fiber and PLLA [5].Coconut fiber reinforced polyethylenecomposites: effect of natural waxy surface layer of the fiber on fiber/matrixinterfacial bonding and strength of composites [6].

Tensile and flexural properties of snake grass natural fiber reinforced isophthallic polyester composites "discussed about the Natural fiber composite materials are one such capable material which replaces the conventional and synthetic materials for the practical applications where we require less weight and energy conservation. The present paper, which emphasis the importance of the newly identified snake grass fibers which are extracted from snake grass plants by manual process $[7,8]$.

Flax fiber and its composites-In the present work, Roselle composites are developed and their mechanical properties are evaluated. Scanning electron micrographs obtained from fractured surfaces were used for a qualitative evaluation of the interfacial properties of Roselle/epoxy and coMPared with glass fiber epoxy. These results indicate that Roselle can be used as a potential reinforcing material for making low load bearing thermoplastic composites [9, 10]. 


\section{Materials and Methods}

\subsection{Selection of Fibers}

In this presnt work, a Roselle fibers (Fig. 1) which is abundantly available in Tamilnadu, India is used. Traditionally, this fibrous material belonging to southern region is being used by the local people for making low cost articles like mats, ropesetc. [11]. The literature review has shown scanty information on the application of this fiber as reinforcing material in the polymer composites.

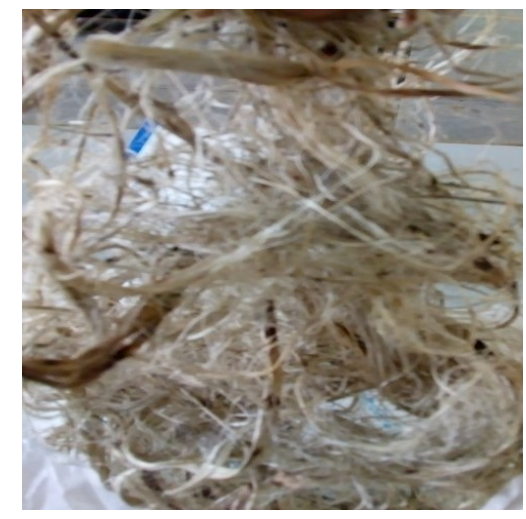

Fig. 1 Roselle Fiber

Extraction of the seed powder from the palm seed is to machined and sieved. The machining of the powder is derived from grinding process. The following Fig. 2 shows the palm seed powder.

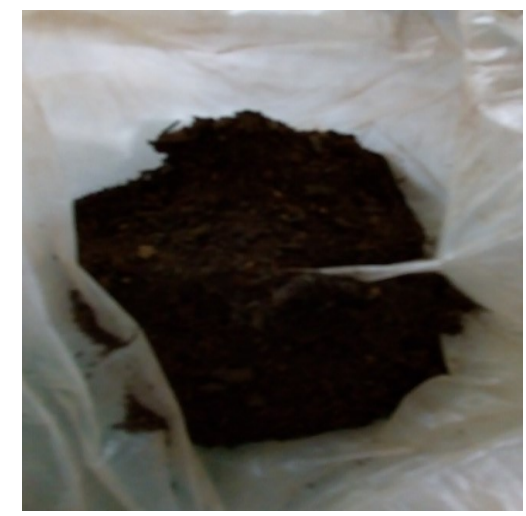

Fig. 2 Palm seed powder

\subsection{Fabrication of composite plate}

Hand lay-up is the simplest and oldest open molding method of the composite fabrication processes. It is a low volume, labor intensive method suited especially for large components, such as boat hulls. Room temperature curing polyesters and epoxies are the most commonly used matrix resins. Curing is initiated by a catalyst in the resin system, which hardens the fiber reinforced resin composite without external heat [18]. For a high quality part surface, a pigmented gel coat is first applied to the mold surface. This technique is also called as contact layup in the open mold method of molding thermosetting resins in association with fiber. First the chopped fibers as per the aspect ratio is laid over the sheet metal tray. The sheet is placed over the rubber and the sides are scaled to protect any leakage using the tape. Then the resin mixed with the above \% of components has to be poured between the space of two plates and after a curing time of about one day the composites can be obtained $[12,13]$.

\subsection{Mechanical property Testing}

The following mechanical properties of the Natural fiber composite materials reinforced with Roselle were determined during this investigation.

i. Tensile Test

ii. Flexural Test

iii. Impact test

iv. Water absorption

\subsubsection{Tensile test}

Tensile test is the maximum stress that a material can withstand while being stretched or pulled before necking, when the specimen's cross-section starts to significantly contract. Tensile test was carried out by applying tensile load. The results from the test are commonly used to select a material for an application, for quality control, and to predict how a material will react under other types of forces. Properties that are directly measured via a tensile test are ultimate tensile strength, maximum elongation and reduction in area. Tensile test was carried out by using universal testing machine $[14,15]$.

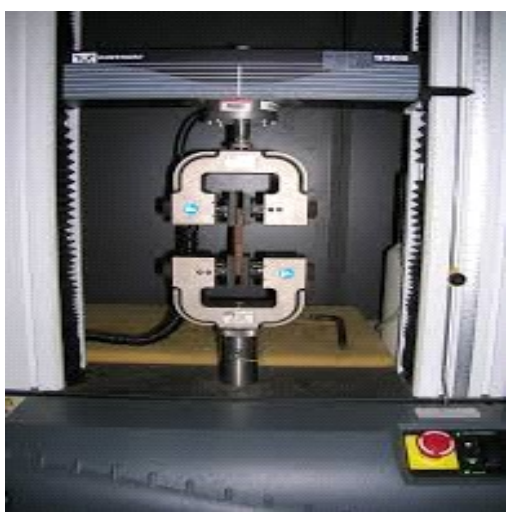

Fig. 3 Tensile test machine 
Testing speed is $2 \mathrm{~mm} / \mathrm{min}$. The specimen size is $165 \mathrm{~mm} \times 9 \mathrm{~mm} \times 5 \mathrm{~mm}$ as per ASTM D638, ISO $527-4$ (Test method for tensile properties of polymer matrix). The volume fraction of fiber of 20 and $30 \%$.Fig. 3 shows the machine of tensile test.Kalpak universal testing machine with the capacity of $100 \mathrm{KN}$.

\subsubsection{Flexural Test}

Flexural test was carried with the three point load of two side supported and load acting on the center of the specimen. By continuously increasing the load acting on the specimen we calculated the deformation of the different volume of fraction. Testing speed is $2 \mathrm{~mm} / \mathrm{min}$.

\subsubsection{Impact Test}

Izod impact testing is an ASTM D 256 standard method of determining the impact resistance of materials. A pivoting arm is raised to a specific height (constant potential energy) and then released. The arm swings down hitting a notched sample, breaking the specimen. The energy absorbed by the sample is calculated from the height the arm swings to after hitting the sample. A notched sample is generally used to determine impact energy and notch sensitivity [16, 17]. The Fig. 4 shows the impact machine.

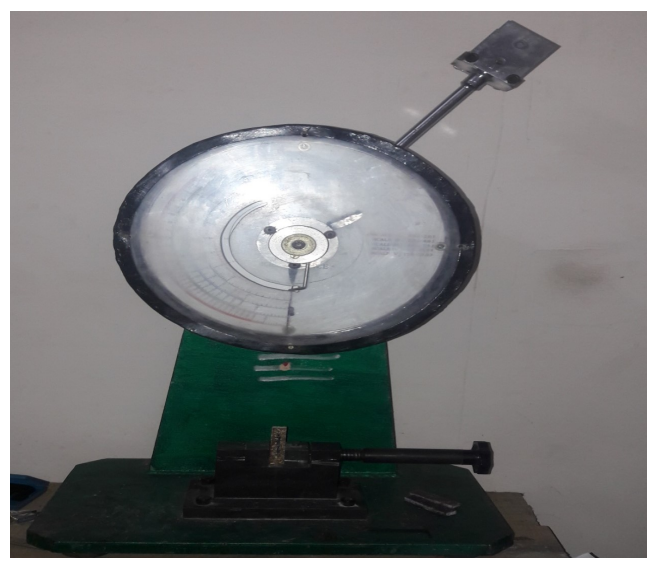

Fig. 4 Impact test machine

\subsubsection{Water absorption test}

The Roselle fiber be dipped into the water and notice the weight of fiber for the period of half an hour and finalized the standard value of water absorption Fig. 5 shows the water absorption test.The initial rate of water absorption and the maximum water uptake increased for all composite specimens as fiber content increased in the composites.

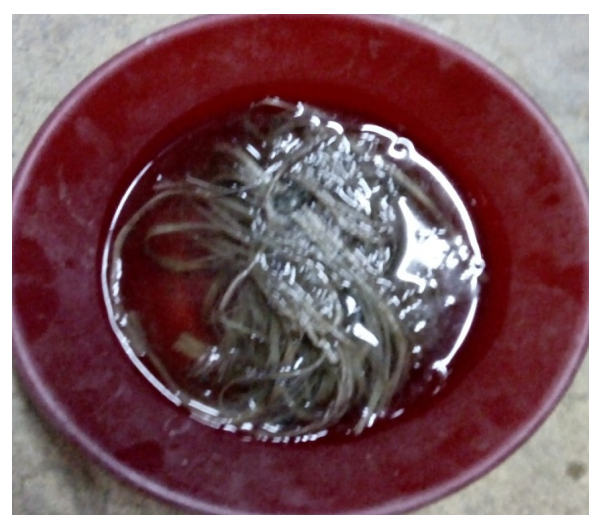

Fig. 5 Water Absorption process

\section{Results and Discussion}

The following Tensile, Flexural, Impact and Water absorption tests results were discussed below.

\subsection{Tensile test}

Tensile tests were conducted for the composite specimen using the universal testing machine to obtain the tensile properties. The dog-bone specimens of the composite were prepared according to the ASTM D638 standards. CoMParing the tensile test of Roselle, palm seed powder and mixture of Roselle and palm seed powder were identified.

It was clear that the mixture of Roselle fiber \&palm seed powder was higher in tensile strength when coMPared with roselle fiber .where the tensile strength of palm seed powder was $9.11 \mathrm{~N} / \mathrm{mm}^{2}$ and the tensile strength of roselle fiber was $10.595 \mathrm{~N} / \mathrm{mm}^{2}$. while coMParing these tensile strength, its deviation was $1.485 \mathrm{~N} / \mathrm{mm}^{2}$. The tensile strength of roselle fiber\& palm seed powder was $14.999 \mathrm{~N} / \mathrm{mm}^{2}$. While coMParing roselle fiber \&palm seed powder with the above mentioned fiber ,Roselle fiber \& palm seed powder consits of high tensile strengthwith the deviation of $4.395 \mathrm{~N} / \mathrm{mm}^{2}$. where these fiber composite contains the same volume fraction of $30 \%$, Fig. 6 shows the effect of tensile strength with different fiber composite In this chart it clearly mention the deviation of the fiber composite. 
Journal of Manufacturing Engineering, March 2021, Vol. 16, Issue. 1, pp 001-006

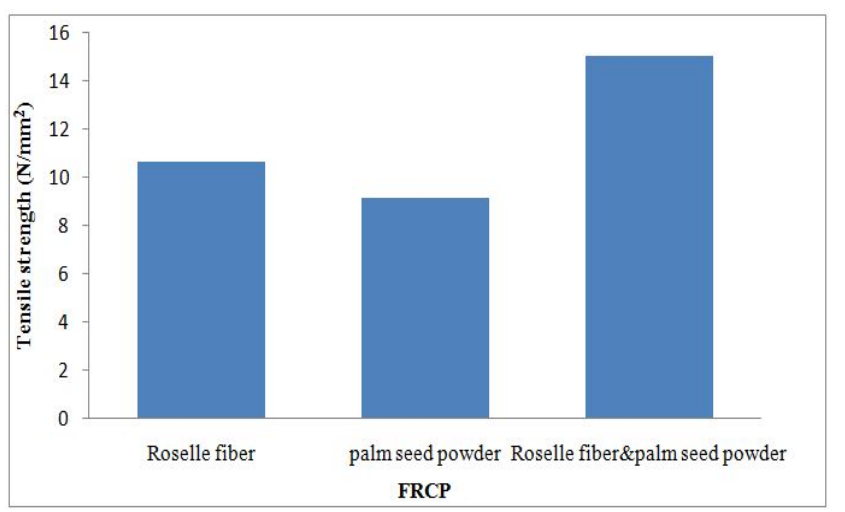

Fig. 6 Effect of Tensile Strength with Different Fiber Composite

\subsection{Flexural Test}

The flexural property is one of the important parameter in composite mainly useful to quantify in structural applications.ASTM D 790: Standard Test Method for Flexural Properties of Polymer Composite. The samples are cut to the dimensions as per ASTM standards for flexural testing. The test specimen geometry as specified in the above standard for balancedsymmetric carbon and glass fiber composites $(0 / 90)$ are , width $12.7 \mathrm{~mm}$, length $127 \mathrm{~mm}$, thickness 6 $\mathrm{mm}$.

Flexural test is done using a three point bend setup. The distance between the two supports are maintained at $100 \mathrm{~mm}$. The ultimate load carrying capacity of the composite laminates is recorded.

It is also noted that the flexural strength depends upon the fiber content, Fig. 7 shows the effect of flexural strength with different fiber composite. Where the fibers were Roselle fiber, palm seed powder and the mixture of Roselle fiber \&palm seed powder, here the volume fraction $30 \%$ it constant for the above three mentioned fiber composite. The chart clearly shows the variation of flexural strength. The flexural of the Roselle fiber was $32.702 \mathrm{MPa}$, the flexural strength of palm seed powder was $30.21 \mathrm{MPa}$ and the mixture of Roselle fiber \& palm seed powder was $37.084 \mathrm{MPa}$. While coMParing these three fiber composite, mixture of Roselle\& palm seed powder contains high flexural strength with the deviation of $4.382 \mathrm{MPa}$ to other to fiber composite.

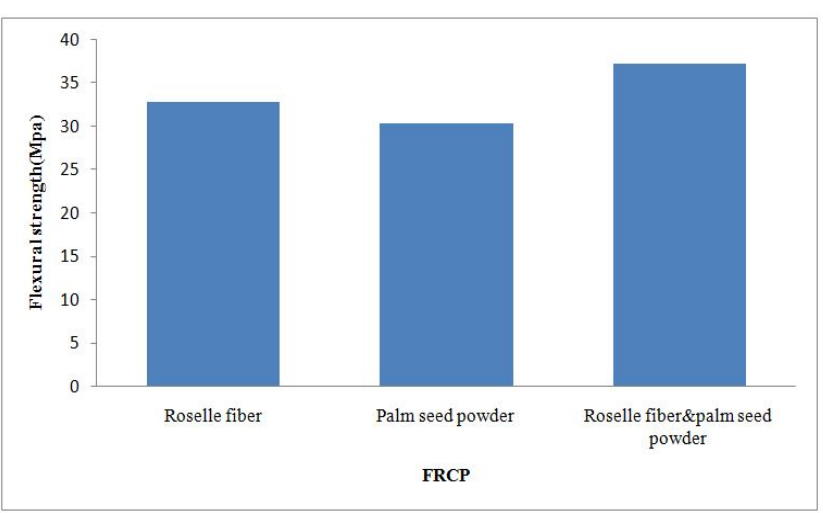

\section{Fig. 7 Effect of Flexural Strength with Different} Fiber Composite

\subsection{Impact Test}

ASTM D 256: Standard test method for impact properties of polymer matrixcomposites. Izod impact strength of composite samples is evaluated as per ASTM D256, using Impact Testing Machine.The test specimen geometry as specified in the above standard for balance symmetric glass and carbon fiber $(0 / 90)$ composites are $64 \mathrm{~mm}$ long $\times 12.7 \mathrm{~mm}$ wide $\times 3$ $\mathrm{mm}$ thick.The Izod test specimens are clamped in an upright position so that the end of the specimen faced its striking edge and impact energy absorbed for breaking the specimen is directly obtained. Impact strength is calculated using the expression. Fig. 8 shows the impact strength of the different fiber composite, here clearly viewed the deviation of the fiber strength, where Roselle and palm seed powder have higher strength capacity coMPare to other.

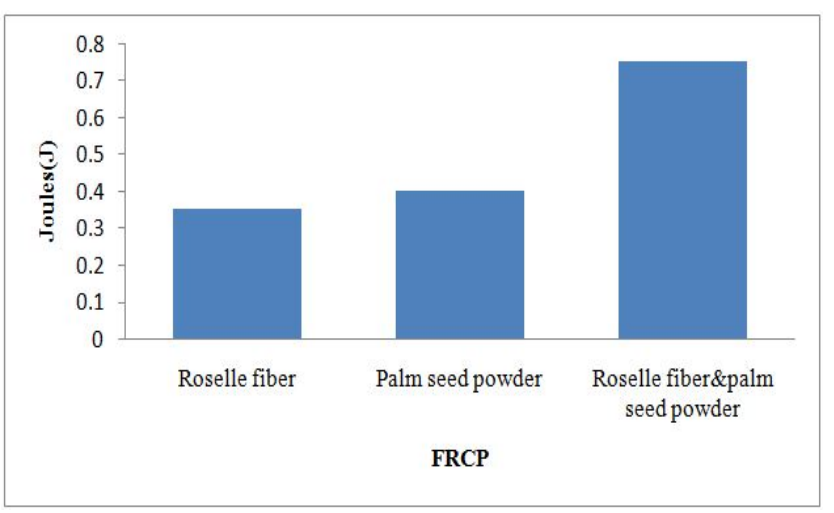

Fig. 8 Impact Strength of Fiber Composite 


\subsection{Water absorption Test}

In these water absorption test we dipped the Roselle fiber and Palm seed fiber into the water and notice that stripping of water. The moisture absorption increased with increasing fiber content in all the cases. The water absorption for all specimens is linear and then slows till it approaches saturation point in the beginning.

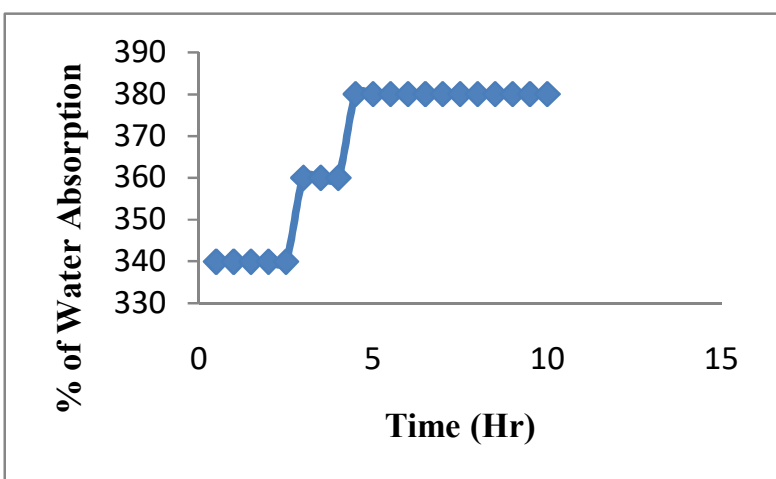

\section{Fig. 9 Water Absorption Curve for Different Fiber}

Composite Impact Strength of Fiber Composites

The above Fig. 9 shows the water absorption of Roselle fiber and palm seed powder. The graph clearly shows the value of absorption ,first fiber suddenly stripped the water and it gradually increase for an time but in certain period of time it should remainconstant, that process be mentioned above graph.

\section{Conclusions}

The present work shows the Roselle fiber \& palm seed powder will become a future alternative for the conventional materials due to its mechanical properties and availability. The following conclusion are based on the experimental study.

The Tensile strength of Roselle fiber \& palm seed powder is higher than other natural fiber composite.

The ultimate tensile strength of Roselle fiber \& palm seed powder composite is $14.990 \mathrm{~N} / \mathrm{mm}^{2}$, which is higher than that of other two fiber composite.

The percentage elongation of Roselle fiber \& palm seed powder is $3.110 \%$ which is higher than other two fiber and the values are $2.490 \% \& 2.310 \%$.

The flexural strength is $37.084 \mathrm{Mpa}$ of Roselle fiber \& palm seed powder which is higher than other two fiber composite. Hence it has good flexural properties.

Roselle fiber \& palm seed powder has excellent ability to absorb impact force where it absorbs $0.75 \mathrm{~J}$ energy which is greater than other two fiber composite. Hence it can be inferred that cracks cannot propagate.

In the water absorption test, the absorption of water content is less and remains constant weight at the period of $4.5 \mathrm{hrs}$ at $380 \%$.

Overall it can be concluded that the composite of Roselle fiber \& palm seed powder have the maximum mechanical properties, it can be extracted with lowcost.

\section{References}

1. Verma, D., Gope, P.C., Shandilya, A., Gupta, A. and Maheshwari, M.K., 2013. Coir fibre reinforcement and application in polymer composites. J. Mater. Environ. Sci, 4(2), pp.263-276.

2. Sakthi Vadivel, $K$ Sivaraj, $C$ Mohanraju, $M$, Govindasamy, P., 2020, "Machinability Study of Column Cactus Fiber Reinforced Polymer Composite Materials", International Research Journal of Engineering and Technology, Vol. 7(5), Pg. No. 1134.

3. Sakthi Vadivel, K. and Govindasamy, P., 2020. Thermal analysis of Acacia Arabica and Pencil Cactus fiber hybrid polymer composites. Res. J. Chem. Environ, 24, p.52.

4. Sakthi Vadivel, K and Govindasamy, P., 2020, "Electrical properties of alkali treated Acacia and Cactus fiber reinforced hybrid polyester composites", Journal of Electrical Engineering, ISSN 1582-4594, Vol. 20(2), Pg. No. 76-81.

5. Nishino, T., Hirao, K., Kotera, M., Nakamae, K. and Inagaki, H., 2003. Kenaf reinforced biodegradable composite. Composites science and technology, 63(9), pp.1281-1286.

6. Brahmakumar, M., Pavithran, C. and Pillai, R.M., 2005. Coconut fibre reinforced polyethylene composites: effect of natural waxy surface layer of the fibre on fibre/matrix interfacial bonding and strength of composites. Composites Science and technology, 65(3-4), pp.563-569.

7. Sathishkumar, T.P., Navaneethakrishnan, P., Shankar, S., Rajasekar, R. and Rajini, N., 2013. Characterization of natural fiber and composites-A review. Journal of Reinforced Plastics and Composites, 32(19), pp.1457Reinforced Plastics and Composites, 32(19), pp.145
1476.

8. Razali, N., 2016. Development and Characterization of Roselle Fibre Reinforced Vinyl Ester Composites (Doctoral dissertation, School of Graduate Studies, Universiti Putra Malaysia).

9. Yan, L., Chouw, N. and Jayaraman, K., 2014. Flax fibre and its composites- $A$ review. Composites Part $B$ : Engineering, 56, pp.296-317.

10. Alavudeen, A., Rajini, N., Karthikeyan, S., Thiruchitrambalam, M. and Venkateshwaren, N., 2015. Mechanical properties of banana/kenaf fiber-reinforced hybrid polyester composites: Effect of woven fabric and random orientation. Materials \& Design (1980-2015), 66, pp.246-257. 
11. Vadivel, K.S. and Govindasamy, P., 2021. Characterization of natural cellulosic fiber from treated acacia arabica and pencil cactus fiber. Materials Today: Proceedings.

12. Boopalan, M., Niranjanaa, M. and Umapathy, M.J., 2013. Study on the mechanical properties and thermal properties of jute and banana fiber reinforced epoxy hybrid composites. Composites Part B: Engineering, 51, pp.54-57.

13. Benitez, A.N., Monzón, M.D., Angulo, I., Ortega, Z. Hernández, P.M. and Marrero, M.D., 2013. Treatment of banana fiber for use in the reinforcement of polymeric matrices. Measurement, 46(3), pp.1065-1073.

14. Orue, A., Jauregi, A., Peña-Rodriguez, C., Labidi, J., Eceiza, A. and Arbelaiz, A., 2015. The effect of surface modifications on sisal fiber properties and sisal/poly modifications on sisal fiber properties and sisal/poly (lactic acid) interface adhesi
Engineering, 73, pp.132-138.
15. Sabinesh, S., Renald, C.T. and Sathish, S., 2014. Investigation on tensile and flexural properties of cotton fiber reinforced isophthallic polyester fiber reinforced isophthallic polyester
composites. International Journal of Current Engineering composites. International Journal
and Technology, 2(2), pp.213-219.

16. Dixit, S. and Verma, P., 2012. The effect of hybridization on mechanical behaviour of coir/sisal/jute fibres reinforced polyester composite material. Research Journal of Chemical Sciences

17. Mir, S.S., Hasan, S.M., Hossain, M.J. and Hasan, M., 2012. Chemical modification effect on the mechanical properties of coir fiber. Engineering Journal, 16(2), pp.7384.

18. Chand, N. and Dwivedi, U.K., 2006. Effect of coupling agent on abrasive wear behaviour of chopped jute fibrereinforced polypropylene composites. Wear, 261(10), pp.1057-1063. 